\title{
TBLR1 is a novel prognostic marker and promotes epithelial-mesenchymal transition in cervical cancer
}

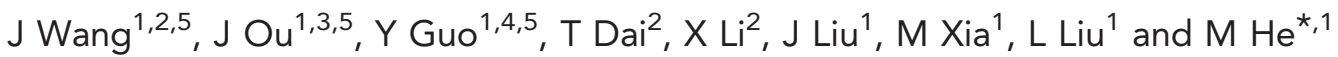

${ }^{1}$ Department of Gynaecology and Obstetrics, The First Affiliated Hospital of Sun Yat-sen University, Guangzhou 510080, People's Republic of China; ${ }^{2}$ State Key Laboratory of Oncology in Southern China, Cancer Center of Sun Yat-sen University, Guangzhou 510060, People's Republic of China; ${ }^{3}$ Center for Reproductive Medicine, The Third Affiliated Hospital of Sun Yat-sen University, Guangzhou 510630, People's Republic of China and ${ }^{4}$ Department of Hepatic Surgery, The Third Affiliated Hospital of Sun Yat-sen University, Guangzhou 510630, People's Republic of China

Background: Invasion and metastasis remain a critical issue in cervical cancer. However, the underlying mechanism of it in cervical cancer remains unclear. The newly discovered protein, TBLR1, plays a crucial role in regulating various key cellular functions.

Methods: In this study, western blot, real-time RT-PCR, immunohistochemical staining, 3D morphogenesis Matrigel culture, wound healing and Boyden chamber invasion assays, xenografted tumour model, luciferase assays, and chromatin immunoprecipitation assays were used.

Results: The expression of TBLR1 in cervical cancer cell lines and tissues was significantly upregulated at both the RNA and protein levels compared with that in normal cervical cells. Statistical analysis suggested that TBLR1 as an independent prognostic factor was significantly correlated with the clinical stage, survival time and recurrence. Moreover, overexpression of TBLR1 in Hela and Siha cell lines promoted invasion in vitro and in vivo with the increases of the mesenchymal factors vimentin and fibronectin and decreases of the epithelial marker $\alpha$-catenin. In contrast, RNAi-mediated knockdown of TBLR1 inhibited epithelialmesenchymal transition in vitro and in vivo. Further study indicated that this might be mediated via the NF- $\kappa \mathrm{B}$ and Wnt/ $\beta$-Catenin signalling pathway, and involve regulation of Snail and Twist.

Conclusions: The TBLR1 protein may be a prognostic marker in cervical cancer and play an important role in the invasion and metastasis of human cervical cancer.

Cervical cancer ranks as the third most frequent female cancer worldwide and the second most frequent in developing countries, where $83 \%$ of cases occur (Jemal et al, 2011). There are an estimated 529800 new cases and 275100 deaths annually (Jemal et al, 2011). In spite of its decreasing incidence and mortality in many countries, associated with wide implementation of Pap smear screening programmes in recent years, cervical cancer remains a critical issue (Kodama et al, 2010; Jemal et al, 2011). The motility and invasiveness of cancer cells play a critical role in the mortality of cervical cancer patients, and provides important information for determining the treatment approach (Kodama et al, 2010; Siegel et al, 2011). Previous reports have shown that proteins such as p38 kinase (Kumar et al, 2010) and heat shock protein 70-2 (Garg et al, 2010) could modulate cancer cell motility and invasiveness, and could serve as prognostic markers for cervical cancer. However, thus far, no sufficiently accurate biomarker for predicting cancer cell aggressiveness preoperatively has been established, and the molecular mechanism underlying

\footnotetext{
*Correspondence: Dr M He; E-mail: drhemian@hotmail.com
}

${ }^{5}$ These authors contributed equally to this work.

Received 4 November 2013; revised 21 April 2014; accepted 30 April 2014; published online 29 May 2014 
cervical cancer invasion and metastasis remains unclear (Noordhuis et al, 2011). Therefore, it is of great clinical value to identify diagnostic markers as well as novel therapeutic strategies.

The newly discovered protein, transducin $\beta$-like protein 1-related protein (TBLR1), was demonstrated to play a key role in mediating the exchange of corepressors, which was also a central aspect in key cellular functions, including growth, anti-apoptosis and inflammation (Hoberg et al, 2004; Perissi et al, 2004). Interestingly, TBLR 1 gene locates on chromosome 3 at $3 \mathrm{q} 26$, and the essential value of detection of genomic amplification of $3 q 26$ in the progression of cervical cancer has been affirmed in several studies (Yang et al, 2001; Andersson et al, 2006). The TBLR1 is a LisH/WD-40-containing protein, originally associated with an $\mathrm{X}$-linked human disorder in which a microdeletion of the C-terminal part of the TBLR1 gene was suggested to be responsible for the hearing defect (An et al, 2003; Perissi et al, 2004). In addition, TBLR1 was initially identified as a component of the SMRT/N-CoR corepressor complexes that regulate multiple signal transduction pathways and gene transcriptions, including the Wnt/ $\beta$-catenin, NF- $\kappa \mathrm{B}$, Notch and nuclear receptor pathways (Zhang et al, 2002; Li and Wang, 2008; Perissi et al, 2008). In addition, Hela cells have been used as materials to show that histone deacetylase 3 includes TBLR1 localises to the mitotic spindle and is required for kinetochore-microtubule attachment (Ishii et al, 2008). Moreover, TBLR1 expression was upregulated in human primary lung squamous cell carcinoma, breast cancer and colon cancer cells, suggesting that TBLR1 is involved in promoting tumour progression or blocking apoptosis (Hoberg et al, 2004; Perissi et al, 2008; Choi et al, 2011). However, there has been no report on the expression of TBLR1 is correlated with clinical staging or cancer patient survival as a potential oncogene.

In this study, we report that TBLR1 expression was associated with cell aggressiveness, pelvic lymph node metastasis and prognosis in stage Ia2-IIa2 cervical patients, and induced by activating NF- $\kappa \mathrm{B}$ and $\mathrm{Wnt} / \beta$-catenin pathways further to regulate the expressions of Snail and Twist in cervical cancer. Thus, TBLR1 is of great clinical value as a potential early biomarker to improve the diagnosis and prognostic assessment of cervical cancer patients.

\section{MATERIALS AND METHODS}

Patient information. The current retrospective study enrolled 194 patients diagnosed with cervical cancer who underwent radical hysterectomy and lymphadenectomy in the Department of Gynecology and Obstetrics, the First Affiliated Hospital, Sun Yat-sen University from March 2000 to September 2010. All the enrolled patients were in the Ia2-IIa2 stage. The mean patient age was $42.00 \pm 8.94$ (range 21-70). Six fresh cervical cancer and paired adjacent noncancerous cervical tissues (ANTs) were collected for quantitative PCR (qPCR) and western blotting analysis. Prior written consent of the patients for the use of these clinical materials for research purposes and approval from the Institutional Ethical Board were obtained. The clinical information is summarised in Supplementary Data and Supplementary Table 1.

Cell lines and plasmids. Primary cultures of normal cervical epithelial cells (NCECs) were established from fresh specimens of patients without cervical lesion as described previously (Song et al, 2009). The cervical cancer cell lines Hela, Siha, ME180 (TBLR1-high), Hela229, C33A (TBLR1-low), Caski and MS7501 were purchased from the American Type Culture Collection (Manassas, VA, USA) and kept in our laboratory. All cell lines were cultured in RPMI-1640 medium (Gibco BRL, San Francisco, CA, USA). Media were supplemented with $10 \%$ fetal bovine serum and $1 \%$ antibiotics in a $5 \% \mathrm{CO}_{2}$-humidified atmosphere at $37^{\circ} \mathrm{C}$.
The pMSCV/TBLR1-overexpressing human TBLR1 was generated by subcloning the PCR-amplified human TBLR1 coding sequence into pMSCV vector. To silence endogenous TBLR1, two RNAi oligonucleotides were cloned into the pSuperretro-puro vector to generate pSuper-retro-TBLR1-RNAi(s), respectively. The cloning primers and RNAi oligonucleotides used are shown in Supplementary Data. The pBabe-Puro-I $\kappa \mathrm{B} \alpha$ mu (plasmid 15,291)-expressing mutant $\mathrm{I} \kappa \mathrm{B} \alpha$ was from Addgene (Cambridge, MA, USA). Tcf-4 siRNA was synthesised by Shanghai Genepharma (Shanghai, China). Stable cell lines expressing TBLR1 or TBLR1 shRNA were selected for 10 days with $0.5 \mu \mathrm{g} \mathrm{ml}^{-1}$ puromycin $48 \mathrm{~h}$ after infection. After 10-day selections, the cell lysates prepared from the pooled population of cells in sample buffer were fractionated on sodium dodecyl sulfate-polyacrylamide gel electrophoresis for the detection of TBLR1 protein level.

The 3D morphogenesis Matrigel culture, wound healing and Boyden chamber invasion assay. The 24 -well dishes were coated with growth factor-reduced Matrigel (BD Biosciences, Franklin Lakes, NJ, USA) and covered with growth medium supplemented with $2 \%$ Matrigel. Cells were serum starved for $24 \mathrm{~h}$ and then seeded at $2 \times 10^{4}$ cells per well, and the medium was replaced with 2\% Matrigel for 3-4 days. Then, microscopic images were captured at 2-day intervals for 2 weeks. For the wound-healing assay, the stable Hela and Siha cell were seeded in six-well plates and grown under permissive conditions until reaching $90 \%$ confluence. The cells were then serum starved for $24 \mathrm{~h}$, and a linear wound was created in the confluent monolayer using a pipette tip. Wounds were observed and photographed immediately (time 0) and thereafter at 24 and $48 \mathrm{~h}$. Each experiment was repeated at least three times. In the Boyden chamber invasion assay, $2 \times 10^{4}$ cells were seeded into $8 \mu \mathrm{m}$ pore inserts that were coated with $50 \mu \mathrm{l}$ Matrigel in triplicate wells. After $24 \mathrm{~h}$, the cells that passed through the filter into the lower chamber were fixed with $1 \%$ paraformaldehyde, stained with haematoxylin and counted (10 random $100 \times$ fields per well).

Xenografted tumour model. The female BALB/c nude mice (4-5 weeks of age, $18-20 \mathrm{~g}$ ) were randomly divided into 10 groups ( $n=6 /$ group). The stable cells $\left(5 \times 10^{6}\right)$ including TBLR1 vector, TBLR1, RNAi vector and TBLR1 shRNA 1- and 2-transduced Hela and Siha cells were injected subcutaneously into the dorsal right flank of 10 groups of 4 -week-old female Balb/c nude mice, respectively. Tumours were examined twice weekly; length and width measurements were obtained with calipers, and tumour volumes were calculated using the equation $\left(L \times W^{2}\right) / 2$. On day 30 , animals were killed; tumours were excised, weighed and paraffin embedded. Serial $6.0 \mu \mathrm{m}$ sections were cut and subjected to immunohistochemical staining. All procedures were performed in accordance with ethical committee approval and met the standards required by the United Kingdom Coordinating Committee for Cancer Research (UKCCCR) guidelines. The conduct of all experiments involving mice adhered strictly to the standard as outlined in the guidelines for the welfare and use of animals in cancer research by Workman et al (2010).

Xenograft mouse metastatic model. Hela and Siha stable cells were harvested and washed twice with PBS. The cells $\left(5 \times 10^{6} / 150 \mu\right.$ l per mouse $)$ were injected intravenously into the tail vein of female BALB/c-nu mice, respectively. After 6 weeks, the mice were killed and the lungs were removed, fixed with $3.7 \%$ formaldehyde and sectioned. The number of mice bearing lung foci was determined. The conduct of all experiments involving mice adhered strictly to the standard as outlined in the guidelines for the welfare and use of animals in the cancer research by Workman et al (2010). 
Luciferase assay and chromatin immunoprecipitation (ChIP) assays. These were performed as previously described (Song et al, 2009), and the detailed information was explicated in Supplementary Data.

Statistical analysis. All statistical analyses were carried out using the SPSS 13.0 statistical software (Chicago, IL, USA) package.
The results were expressed as mean \pm standard error. The $\chi^{2}$ test and Fisher's exact test were used to analyse the relationship between TBLR1 expression and the clinicopathological characteristics. Survival curves were plotted by the Kaplan-Meier method and compared using the log-rank test. Survival data were evaluated using univariate and multivariate Cox regression analyses. In all cases, $P<0.05$ was considered statistically significant.
A

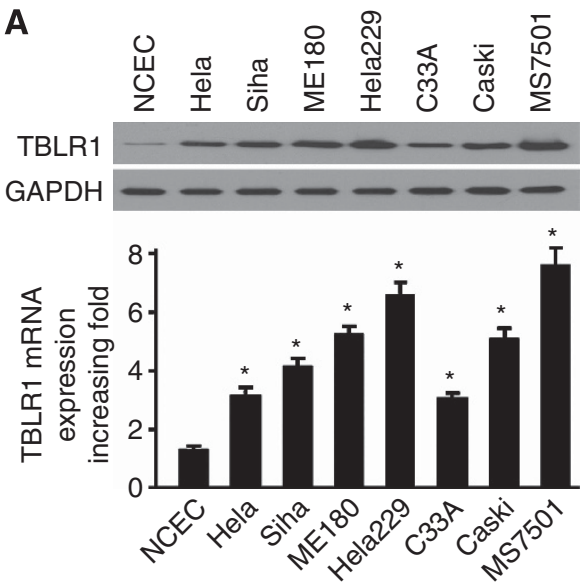

B

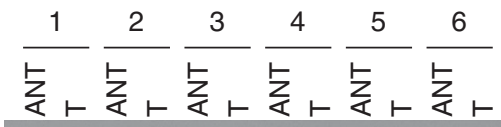

TBLR1

GAPDH

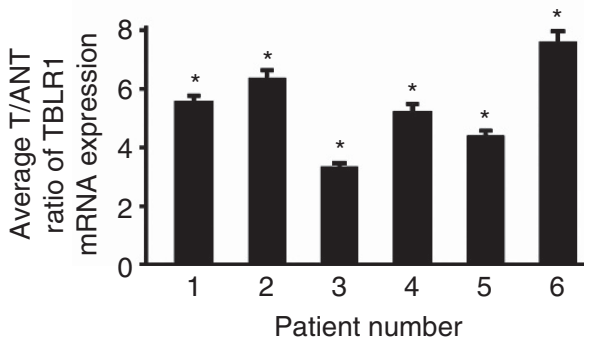

C

Patient 1

Patient 2

Patient 3

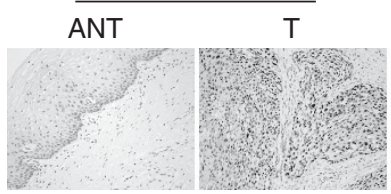

ANT

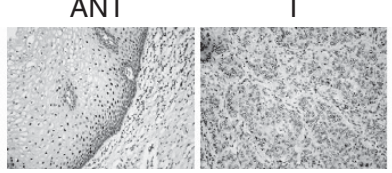

Patient 4

Patient 5

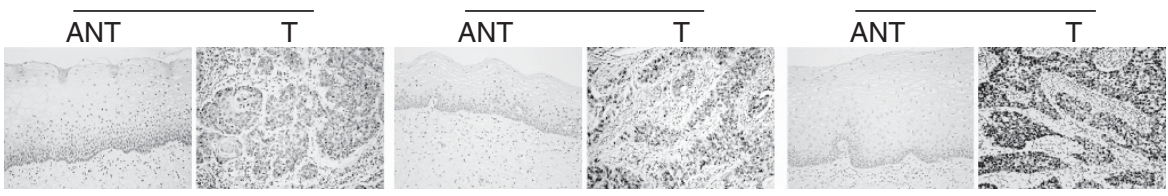

D
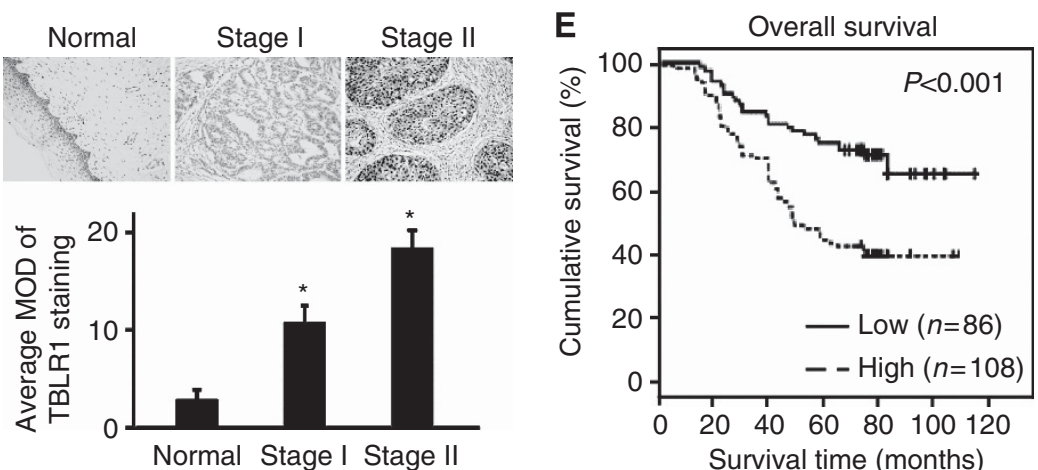

Figure 1. The protein and mRNA expression of TBLR1 determined by western blotting, quantitative PCR (qPCR) and immunohistochemical assay. The expression level was normalised to the expression level of the glyceraldehyde 3-phosphate dehydrogenase (GAPDH) gene expression. The error bars represent s.d. values calculated from three parallel experiments. The protein expression of TBLR1 was determined by immunohistochemical assay and Kaplan-Meier curves obtained from univariate analyses (log-rank) of cervical cancer patients with low vs high TBLR1 expression. Among 194 patients, 108 showed positive TBLR1 staining, mainly in the cytoblast, and partly in the nucleus of cancer cells, whereas the others showed marginal or undetectable TBLR1 staining. (A) Western blotting and qPCR assay of TBLR1 expression in normal cervical epithelial cells (NCECs) and cervical cancer cell lines. (B) Western blotting of TBLR1 protein expression in six pairs of matched cervical cancer (T) and adjacent nontumour cervical tissues (ANTs) with pelvic lymph node metastasis, and T/ANT ratios of TBLR1 mRNA expression quantified by GPCR in six pairs of matched cervical cancer tissues. (C) Immunohistochemical assay of TBLR1 protein expression in six pairs of matched cervical cancer tissues with pelvic lymph node metastasis. (D) TBLR1 expression gradually increased from NCTs to cervical cancer tissues in stage II. The TBLR1 expression was undetectable in NCTs, marginal or moderate in stage I and strong in stage II of cervical cancer tissues. (E) Cumulative survival rate for cases with high vs none or low TBLR1 expression. Survival curves of patients with low vs high expression of TBLR1 ( $n=194$; $P<0.001$, log-rank test); ${ }^{\star} P<0.05$. 
Table 1. Clinicopathological characteristics of patient samples and expression of TBLR1 in cervical cancer and correlation between TBLR1 expression and clinicopathological characteristics of cervical cancer patients $(n=194)$

\section{TBLR1}

\begin{tabular}{|l|c|c|c|c|c|}
\hline & Total & No or low expression, & High expression, & $\begin{array}{c}X^{2} \text { test, } \\
P \text {-value }\end{array}$ & $\begin{array}{c}\text { Fisher's exact test, } \\
P \text {-value }\end{array}$ \\
\hline
\end{tabular}

\section{Gender}

Male

Female

Age (years)

$\geqslant 42$

$<42$

FIGO stage

\begin{tabular}{l}
\hline la2 \\
lb1 \\
lb2 \\
Ila1 \\
Ila2
\end{tabular}

\section{Differentiation grade}

\begin{tabular}{|l|l}
\hline Well & 18
\end{tabular}

Moderate

Poor

Unclear

\section{Types of tumour growth}

Ulcerative

Endophytic

Exophytic

\begin{tabular}{r|r}
18 & $9(50.0)$ \\
86 & $35(40.7)$ \\
66 & $28(42.4)$ \\
24 & $14(58.3)$
\end{tabular}

$41(45.1)$

$45(43.7)$
$0(0.00)$

50 (54.9)

58 (56.3)
1.000

\begin{tabular}{r|r}
$11(61.1)$ & $7(38.9)$ \\
$42(51.9)$ & $39(48.1)$ \\
$14(48.3)$ & $15(51.7)$ \\
$9(39.1)$ & $14(60.9)$ \\
$10(23.3)$ & $33(76.7)$
\end{tabular}

9 (50.0)

51 (59.3)

38 (57.6)

10 (41.7)

0.085

0.848

\section{Pathologic types}

Squamous

Adenocarcinoma

Adenosquamous

18 (46.2)

$23(42.6)$

$45(44.6)$

$\begin{array}{ll}21 & (53.8) \\ 31 & (57.4) \\ 56 & (55.4)\end{array}$

\section{Stromal invasion}

$<1 / 2$

$\geqslant 1 / 2$

$99 \quad 54(54.5)$

17 (39.5)

$60(45.5)$

$9(47.4)$

$26(60.5)$

$72(54.5)$

$10(52.6)$

\section{Lymphovascular space invasion}

Yes

No

46
148

11 (23.9)

$75(50.7)$

35 (76.1)

$73(49.3)$

\section{Pelviclymph node metastasis}

Yes

No

\begin{tabular}{l|l}
67 & $17(25.4)$ \\
127 & $69(54.3)$
\end{tabular}

127

$69(54.3)$

$50(74.6)$

$58(45.7)$

Vaginal involvement

Yes

No

\begin{tabular}{l|r}
11 & $2(18.2)$ \\
183
\end{tabular}

84 (45.9)

9 (81.8)

99 (54.1)

\section{Parametrial infiltration}

\begin{tabular}{|c|c|c|}
\hline Yes & 24 & $6(25.0)$ \\
\hline
\end{tabular}

No

170

$80(47.1)$

$18(75.0)$

$90(52.9)$

\begin{tabular}{l|l}
0.764 & 0.786
\end{tabular}

\section{Positive surgical margins}

\begin{tabular}{|c|c|c|}
\hline Yes & 22 & 7 (46.2) \\
\hline No
\end{tabular}

No

\begin{tabular}{l|r}
22 & $79(45.9)$
\end{tabular}

15 (53.8)

$93(54.1)$

0.210

0.258 


\section{TBLR1}

\begin{tabular}{|l|c|c|c|c|c|}
\hline & Total & No or low expression, & High expression, & $\begin{array}{c}X^{2} \text { test, } \\
P \text {-value }\end{array}$ & $\begin{array}{c}\text { Fisher's exact test, } \\
P \text {-value }\end{array}$ \\
\hline
\end{tabular}

High-risk HPV infection

\begin{tabular}{|l|l|l}
\hline Yes & 118 & $41(34.7)$
\end{tabular}

\begin{tabular}{|r|r|r} 
No & 76 & $31(40.8)$ \\
\hline
\end{tabular}

77 (65.3)

45 (59.2)

\section{Postoperative adjuvant therapy}

\begin{tabular}{|l|r|r}
\hline Chemotherapy & 110 & $40(36.4)$ \\
Radiation & 41 & $21(51.2)$ \\
Both & 35 & $16(45.7)$ \\
Yes (total) & 133 & $57(42.9)$ \\
No & 61 & $29(47.5)$
\end{tabular}

$70(63.6)$

20 (48.8)

$19(54.3)$

$76(57.1)$

32 (52.5)
0.001

$0.001 \quad 0.001$

\section{Recurrence}

\begin{tabular}{|c|c|c|c|c|c|}
\hline $\begin{array}{l}\text { Yes } \\
\text { No }\end{array}$ & $\begin{array}{r}72 \\
122\end{array}$ & $\begin{array}{l}24(33.3) \\
62(50.8)\end{array}$ & $\begin{array}{l}48(66.7) \\
60(49.2)\end{array}$ & 0.018 & 0.025 \\
\hline \multicolumn{6}{|l|}{ Vital status at follow-up } \\
\hline $\begin{array}{l}\text { Alive } \\
\text { Death for cervical cancer }\end{array}$ & $\begin{array}{r}103 \\
91\end{array}$ & $\begin{array}{l}60(58.3) \\
26(28.6)\end{array}$ & $\begin{array}{l}43(41.7) \\
65(71.4)\end{array}$ & $<0.001$ & $<0.001$ \\
\hline
\end{tabular}

Abbreviations: $\mathrm{FIGO}=$ International Federation of Gynecology and Obstetrics; HPV = human papillomavirus; TBLR1 = transducin $\beta$-like protein 1-related protein. $P$-values $<0.05$ are indicated in bold.

\section{RESULTS}

Elevated expression of TBLR1 in cervical cancer cells at both mRNA and protein levels. The expressions of both the TBLR1 protein and mRNA were markedly upregulated in multiple cervical cancer cell lines, including Hela, Siha, ME180, Hela229, C33A, Caski and MS7501, in comparison with those in NCEC (Figure 1A). Furthermore, comparative analysis showed that TBLR1 mRNA and protein levels were differentially upregulated more than two-fold in all six cervical cancer samples compared with matched normal ANTs (Figure 1B). The upregulation of TBLR1 in these clinical samples was further verified by IHC analysis (Figure 1C). Taken together, our results indicated that TBLR1 was upregulated in cervical cancer.

TBLR1 expression is associated with the clinical characteristics of cervical cancer. To further investigate the clinical relationship between TBLR1 protein expression and cervical cancer progression, the expression of TBLR1 was examined by IHC in paraffinembedded, archived clinical tumour tissue specimens obtained from 194 cases of cervical cancer, including 18 cases of stage Ia2 (9.3\%), 81 cases of stage Ib1 (41.8\%), 29 cases of stage Ib2 (14.9\%), 23 cases of IIa1 (11.9\%), 43 cases of IIa2 (22.1\%) and 10 normal cervical tissue (NCT) samples.

The IHC staining showed that TBLR1 expression in cervical cancer increased with advanced clinical stage (Figure 1D). Quantitative analysis of IHC staining showed the level of TBLR1 protein significantly increased in all types of cervical cancer (Supplementary Figure 1), and the percentage of patients expressing TBLR1 increased from stage Ia2 to stage IIa2, but was absent in NCT (Table 1). Statistical analysis revealed that TBLR1 levels were strongly expressed in 55.7\% (108 out of 194) of patients with cervical cancer and was strongly associated with FIGO stage $(P=0.017)$, stromal invasion $(P=0.003)$, lymphovascular space invasion $(P=0.001)$, pelvic lymph node metastasis $(P<0.001)$, parametrial infiltration $(P=0.042)$, high-risk human papillomavirus (HPV) infection $(P=0.001)$, postoperative adjuvant chemotherapy $(P=0.011)$, recurrence $(P=0.018)$ and patient survival $(P<0.001)$ of cervical cancer (Table 1). Significant correlations were identified between TBLR1 expression level and several prognostic risk factors by Spearman's correlation analysis, including FIGO stage $(P=0.001)$, stromal invasion $(P=0.003)$, lymphovascular space invasion $(P=0.001)$, parametrial infiltration $(P=0.042)$, pelvic lymph node metastasis $(P<0.001)$, high-risk HPV infection $(P=0.001)$, postoperative adjuvant chemotherapy $(P=0.01)$ and survival time $(P=0.003)$ (Supplementary Table 2$)$. Univariate and multivariate Cox regression analyses showed that TBLR1 expression $(P=0.032)$, FIGO stage $(P=0.007)$, pelvic lymph node metastasis $(P=0.027)$ and recurrence $(P<0.001)$ were independent prognostic factors that influenced survival (Supplementary Table 3). There was no obvious relationship with age, differentiation grade, types of tumour growth, pathological types, vaginal involvement, positive surgical margins or postoperative adjuvant radiation (Table 1).

Moreover, Kaplan-Meier survival curves and the log-rank test survival analysis showed that the overall survival of patients with high levels of TBLR1 was significantly poorer than patients with low levels of TBLR1 $(P<0.001$; Figure 1E). In addition, similar results were obtained in subgroups of patients with squamous cell carcinoma, adenocarcinoma and adenosquamous carcinoma (Supplementary Figure 2A-C). The Cox regression model revealed that TBLR1 expression (relative risk: 1.720, CI 1.061-2.787, $P=0.028$ ), FIGO stage (relative risk: 1.192, CI 1.061-1.399, $P=0.031$ ), pelvic lymph node metastasis (relative risk: 1.736 , CI $1.064-2.833, P=0.027$ ) and recurrence (relative risk: 5.852, CI 3.662-9.350, $P<0.001$ ) were risk factors (Supplementary Table 3). Collectively, these data demonstrated TBLR1 was linked to the clinical progression of cervical cancer and might represent a valuable prognostic marker for cervical cancer.

TBLR1 overexpression correlates with pelvic lymph node metastasis and clinical progression in cervical cancer. Patient survival analysis showed a clear positive correlation between pelvic lymph node metastasis and the overall survival in patients with cervical cancer $(P<0.001$, Supplementary Figure 2D). 
The cumulative 5-year overall survival for patients with pelvic lymph node metastasis was $45.4 \%$, whereas in patients with no pelvic lymph node metastasis the rates were $77.9 \%$. In addition, statistical analyses revealed that TBLR1 expression strongly correlated with pelvic lymph node metastasis $(P<0.001$; Table 1), suggesting that TBLR1 overexpression is associated with the progression of human cervical cancer.

Upregulation of TBLR1 promotes cervical cancer cell EMT. In light of the obvious connection between TBLR1 expression and pelvic lymph node metastasis, we further investigated the effect of TBLR1 on invasion and metastasis in Hela and Siha cervical cancer cells. As shown in Figure 2A, Hela and Siha cells were established to stably overexpress TBLR1. Interestingly, in wound healing assays, Hela-TBLR1 and Siha-TBLR1 cells migrated and almost filled the gap $48 \mathrm{~h}$ after wounding; however, the gap filling was significantly retarded in the control cells, indicating that TBLR1 promoted the migration properties of Hela and Siha cells (Figure 2D). Moreover, MTT assays of the stable cell lines made it more persuasive by revealing no statistically significant differences in cell proliferation among the stable cell lines $(P>0.05$, Supplementary Figure 3$)$. Similar results were found in the Boyden chamber assays, another method used to test the migration and metastatic properties of cells (Figure 2C). In addition, 3D spheroid invasion assay revealed that TBLR1transduced cervical cell lines cultured in Matrigel for 9 days displayed morphologies typical of highly aggressive invasiveness, presenting more outward projections from practically all individual cells, compared with vector control cells (Figure 2B). Moreover, the capability of TBLR1 to promote cervical cancer progression was further verified in vivo. The tumours formed by TBLR1-transduced cervical cancer cells were larger and and had more weight than vector control tumours (Figure $2 \mathrm{E}$ ). To further investigate the molecular mechanism mediating the aggressive effect of TBLR1, the levels of epithelial-mesenchymal transition (EMT) markers were examined. Western blotting analysis and immunofluorescence assays revealed that mesenchymal factors vimentin and fibronectin were significantly upregulated and the expression of epithelial marker $\alpha$-catenin was partially rescued in the TBLR1transduced Hela and Siha cells (Figure 3A and B). Nevertheless, Hela and Siha cells were originally E-cadherin-negative cell lines; therefore, Caski and ME180 cells, as E-cadherin-positive cells, were used in further western blotting analysis to identify whether the expression of the epithelial marker E-cadherin was influenced by TBLR1 in EMT. The TBLR1-transduced Caski and ME180 cervical cancer cells showed visibly downregulated expression of E-cadherin and $\alpha$-catenin, whereas the expressions of vimentin and fibronectin were upregulated (Supplementary Figure 4). In addition, IHC analysis of the special tumours excised from the four groups of mice, respectively, showed that TBLR1-overexpressing tumours displayed increased expressions of vimentin and fibronectin and lower expressions of $\alpha$-catenin compared with vector control tumours (Figure 3C). To further quantify metastatic potential in vivo, we performed tail vein xenografts and compared the rates of lung colonisation. The upregulation of TBLR1 expression resulted in a significant increase in the number of lung metastatic nodules (Figure $4 \mathrm{~A}$ and $\mathrm{B}$ ). In brief, upregulation of TBLR1 promotes cervical cancer cell EMT in vitro and in vivo.

Downregulation of TBLR1 inhibited cervical cancer cell EMT. To further demonstrate the significance of the pro-EMT function of TBLR1 in cervical cancer cells, the Hela and Siha cells were infected with empty vector alone and the two shRNAs that suppressed endogenous TBLR1 expression stably. As expected, TBLR1 protein levels were decreased in the TBLR1-silenced cells (Figure 5A). Downregulation of TBLR1 reduced the irregular branched structures of both cells in 3D morphogenesis Matrigel cultures that characterised the invasive phonotype (Figure 5B).
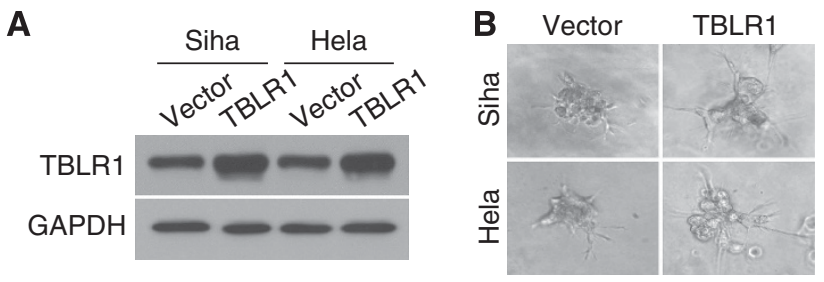

C
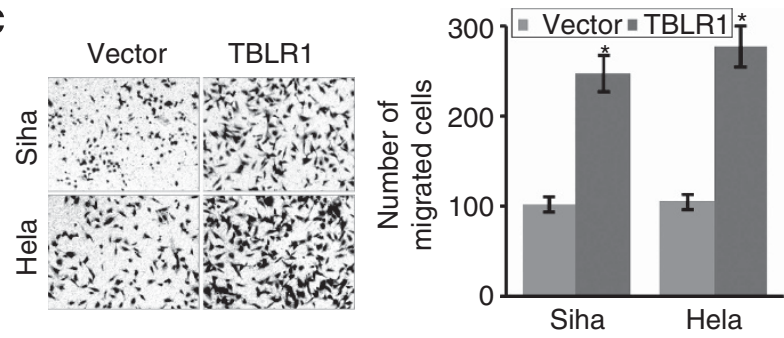

D

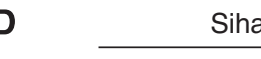

Siha
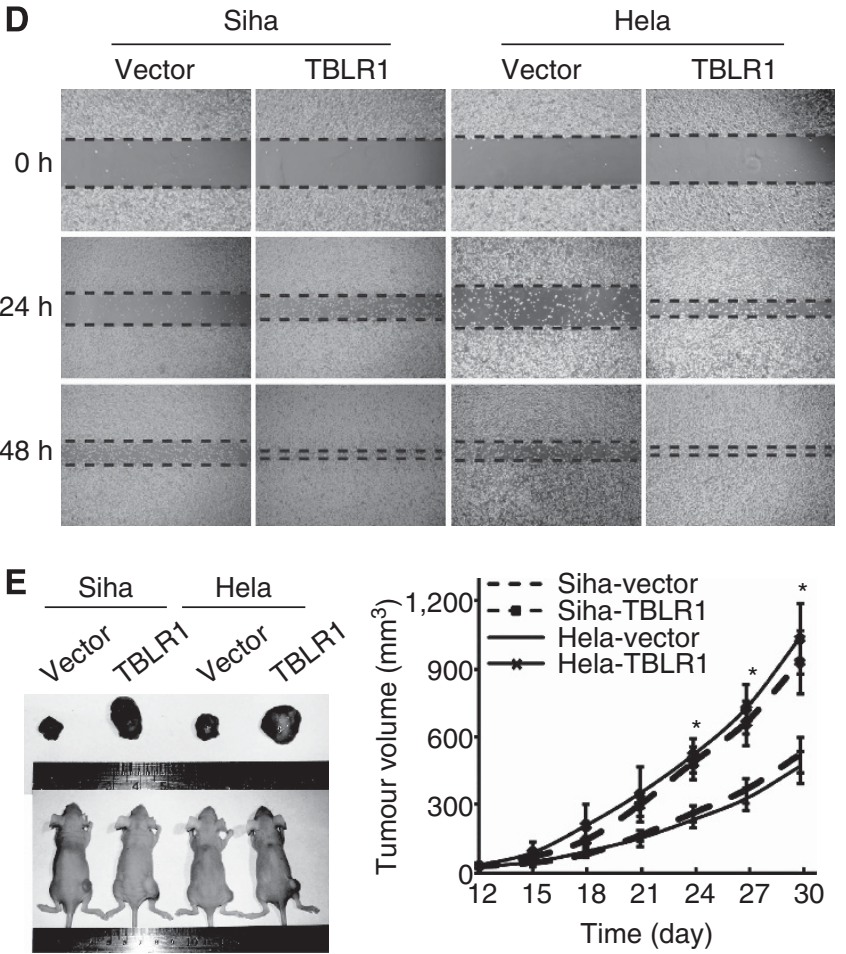

Figure 2. Cell motility and invasion were promoted by TBLR1 overexpression in vitro and in vivo. (A) Western blotting of TBLR1 expression in vector- and TBLR1-transduced Hela and Siha cells. Glyceraldehyde 3-phosphate dehydrogenase (GAPDH) was used as a loading control. (B) The acini formation of cells was tested in 3D morphogenesis Matrigel culture ( $\times 200$ ). (C) The invasive properties induced by fetal bovine serum were analysed by the Boyden chamber invasion assay $\left(\times 200,{ }^{*} P<0.05\right)$. (D) The mobility of cells was measured by testing the rate of wound closure at 0,24 and $48 \mathrm{~h}$ ( $\times 200)$. (E) Effect of TBLR1 on tumour formation in nude mouse xenograft model. A representative picture of tumour growth in nude mice subcutaneously inoculated with vector- and TBLR1-transduced Hela and Siha cells (left). Subcutaneous tumour growth curve of TBLR1transduced Hela and Siha cells in nude mice was compared with vector control Hela and Siha cells in nude mice $(n=6)\left(\right.$ right); ${ }^{\star} P<0.05$.

Moreover, the wound-healing assay and Boyden chamber invasion assay were dramatically inhibited by the ablation of TBLR1 expression (Figure 5C and D and Supplementary Figure 5). Strikingly, no statistically significant differences were found in MTT assays of the stable cell lines either $(P>0.05$, Supplementary Figure 3). 
A

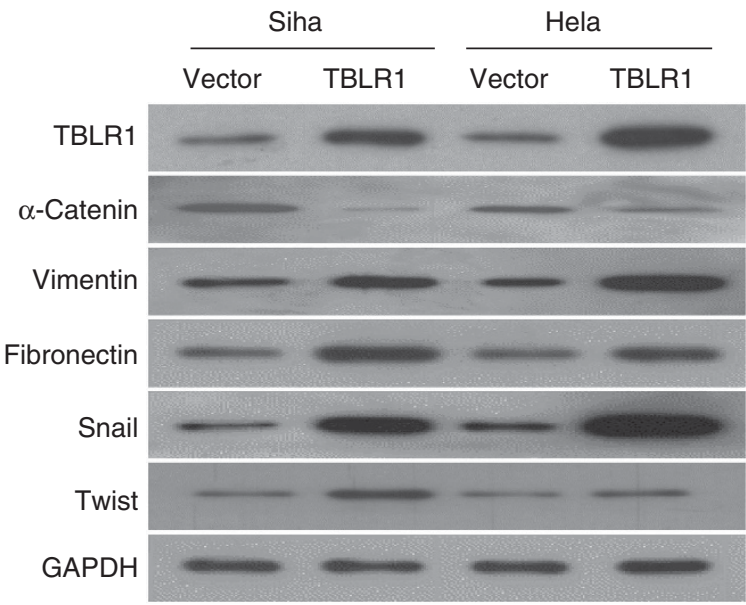

B

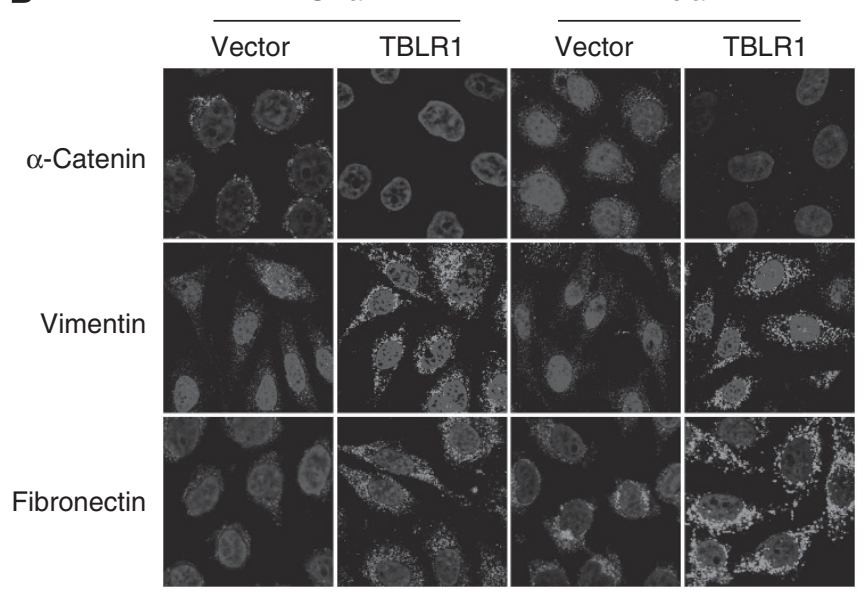

C

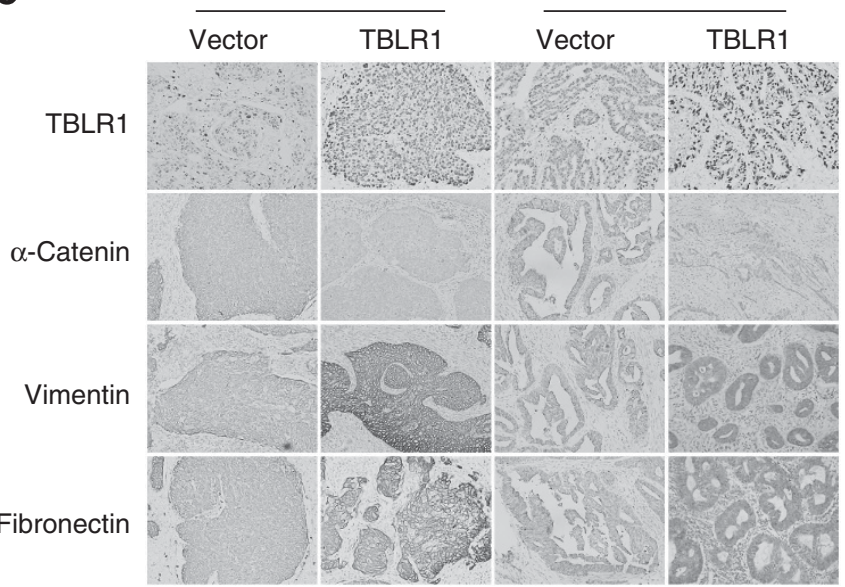

Figure 3. Overexpression of TBLR1 promoted EMT by upregulating the expressions of Snail and Twist in cervical cancer. (A) Western blotting of the expressions of TBLR1 and EMT-relevant markers $\alpha$-Catenin, fibronectin and vimentin, as well as EMT regulators Snail and Twist in the vector- and TBLR1-transduced Hela and Siha cells, respectively. Glyceraldehyde 3-phosphate dehydrogenase (GAPDH) was used as a loading control. (B) Immunofluorescence assay of EMTrelevant markers ( $\alpha$-Catenin, fibronectin and vimentin) $(\times 100)$. (C) The $\mathrm{IHC}$ assay of protein expression of TBLR1 and EMT-relevant markers $(\alpha$-Catenin, fibronectin and vimentin) in the tumours excised from four groups of mice including the vector- and TBLR1-transduced Hela and Siha groups, respectively $(\times 200)$.
However, tumours formed by TBLR1-silenced cells were smaller, in both size and weight, than the tumours formed by shRNA vector cells (Figure 5E). Besides, the mesenchymal markers vimentin and fibronectin were downregulated, whereas $\alpha$-Catenin was markedly overexpressed in TBLR1-silenced cells compared with the control cells (Figure 6A and B). Similar results were obtained in TBLR1silenced Caski and ME180 cells that also showed increased expression of E-cadherin compared with vector control cells (Supplementary Figure 4). Moreover, IHC analysis of mice tumours showed the same trend: decreased expressions of vimentin and fibronectin and increased expressions of $\alpha$-Catenin in TBLR1silenced tumours (Figure 6C). In vivo metastatic assay, lung metastatic foci were present in the experimental mice, but fewer in the groups of mice injected with TBLR1-silenced cells (Figure 4A). Strikingly, the statistical decreases in the number of lung metastatic nodules resulted from downregulation of TBLR1 (Figure 4B). Consequently, these results indicate that downregulation of TBLR1 inhibited cervical cancer cell EMT in vitro and in vivo.

TBLR1 induces EMT by regulating the NF- $\kappa$ B and Wnt/ $\beta$-catenin pathways to upregulate the expressions of Snail and Twist. Combining our results with those of previous studies of the biological function and mechanism of TBLR1 (An et al, 2003; Perissi et al, 2004; Li and Wang, 2008; Choi et al, 2011), we decided to test whether the Snail and Twist protein levels were influenced in the stable Hela and Siha cell lines. Western blotting showed that the expressions of Snail and Twist were significantly higher in TBLR1-overexpressing tumours and lower in TBLR1-silenced tumours than the respective control tumours (Figures $3 \mathrm{~A}$ and $6 \mathrm{~A}$ ). Further experiments showed that overexpressing TBLR1 significantly enhanced, but silencing TBLR1 reduced, the activities of NF$\kappa \mathrm{B}$ and $\mathrm{Wnt} / \beta$-Catenin luciferase reporters as well as affected the expression levels of their downstream proteins Snail and Twist (Figure 7A and B). To further investigate the mechanism by which TBLR1 promotes cervical cancer pathogenesis, the effects of blocking the NF- $\kappa \mathrm{B}$ and $\mathrm{Wnt} / \beta$-Catenin pathway on TBLR1induced aggressiveness were examined. As shown in Figure $7 \mathrm{C}$ and $\mathrm{D}$, either overexpressing an $\mathrm{I} \kappa \mathrm{B} \alpha$ dominant-negative mutant $(\mathrm{I} \kappa \mathrm{B} \alpha$ $\mathrm{mu}$ ) or silencing TCF4 by RNA interference could significantly decrease the expression levels of EMT regulators, including Snail and Twist, as well as the expression of EMT markers, including vimentin and fibronectin. Intriguingly, the stable Hela and Siha TBLR1-overexpressing cells treated with both $\mathrm{I} \kappa \mathrm{B} \alpha-\mathrm{mu}$ and TCF4RNAi showed more significant deregulations of Snail, Twist and the expressions of vimentin and fibronectin (Figure 7C and D). Moreover, by performing a ChIP assay, we found that TBLR1 bound to regions 1 and 5 within the snail promoter but regions 2, 4 and 7 within the Twist promoter (Figure 7E). Therefore, TBLR1 might regulate EMT to induce cervical cancer cell aggressiveness and lymph node metastasis through the NF- $\kappa \mathrm{B}$ and $\mathrm{Wnt} / \beta$-catenin pathways by regulating the expressions of Snail and Twist.

\section{DISCUSSION}

Our results indicate that TBLR1 has the potential to act as a novel predictor of pelvic lymph node metastasis and recurrence in cervical cancer patients. The standard treatment of early-stage cervical cancer patients is radical hysterectomy plus lymphadenectomy or chemoradiation (Benedet et al, 2000). Adjuvant therapies are required for patients with lymph node metastasis that would make the initial surgical procedure unnecessary in retrospect (Benedet et al, 2000; Selman et al, 2008). Thus, the FIGO guidelines have been used to categorise patients into a high-risk group and an intermediate-risk group according to the pathological risk factors, including positive pelvic lymph nodes, microscopic parametrical invasion, tumour-positive resection margins 

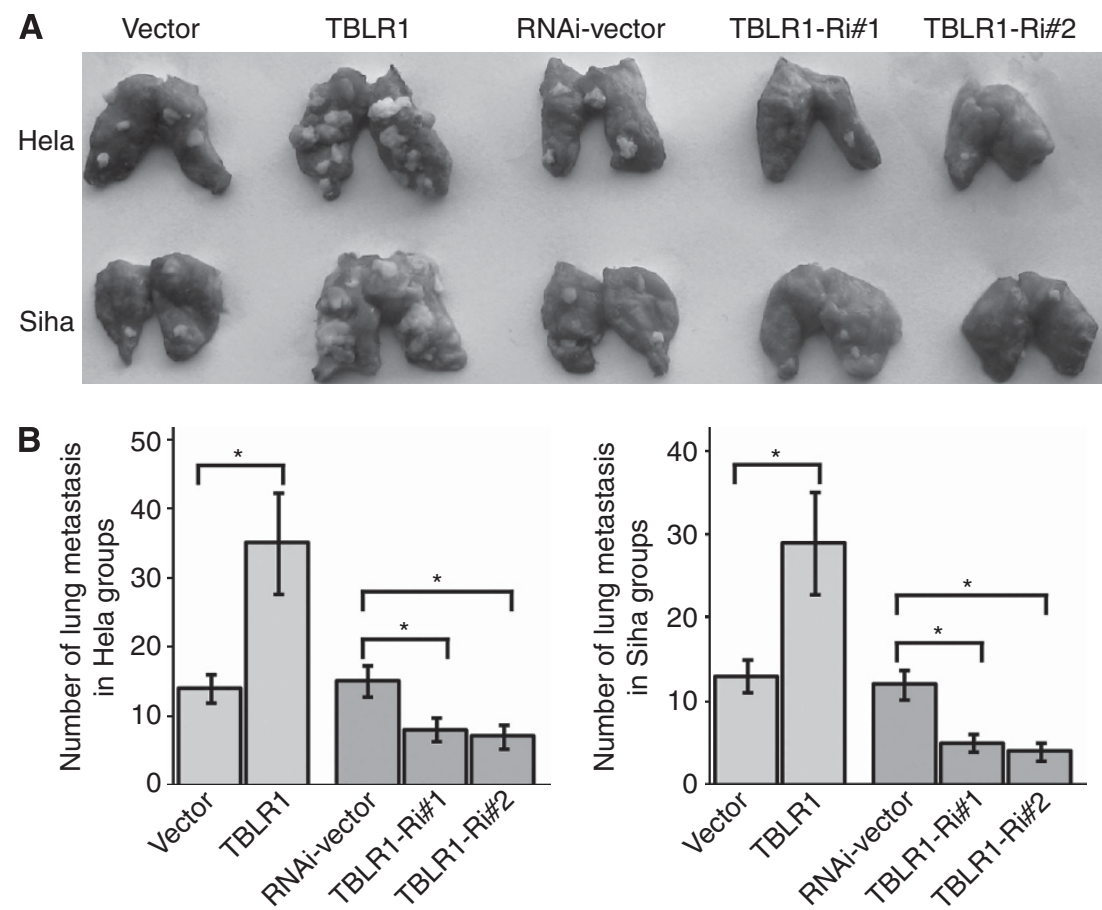

Figure 4. Results of a xenograft mouse metastatic model. The metastatic capacity was increased on TBLR1 overexpression and decreased on TBLR1 knockdown. (A) Lungs removed from mice injected with the indicated cells. (B) The numbers of metastatic tumours were counted. ${ }^{*} P<0.05$.

and deep stromal invasion (Biewenga et al, 2011), that can subsequently affect the decision to perform adjuvant therapy. Among these factors, pelvic lymph node metastases are the most important postoperative risk factor for recurrence or failure to survive, and thus require adjuvant therapy (Kodama et al, 2010; Biewenga et al, 2011; Chen et al, 2013). Unfortunately, gynaecological oncologists could not determine treatment properly because the sentinel lymph node biopsy as a promising technique failed to show sufficiently accuracy to detect micrometastases with a high false negative rate as well as the imaging methods (Altgassen et al, 2008; Selman et al, 2008; Slama et al, 2013).

As treatment strategies are very limited for metastatic and recurrent cervical cancer, the upregulated TBLR1 identified in our study is a potential marker and target for formulating treatment strategies. In this study, the accuracy of predicting pelvic lymph node metastasis by investigating TBLR1 expression level in our cohort was $35.2 \%$ (38 out of 108). However, in patients who demonstrated high expression of TBLR1, but were not detected with lymph node metastasis, the recurrence rate reached $31.4 \%$, whereas the rate of recurrence was only $18.5 \%(P<0.05)$ in the group of low expression of TBLR1. Given that the reported pelvic lymph node micrometastasis rate in early-stage cervical cancer patients was 15\% (Wangsa et al, 2009), it is highly likely that the 'real' accuracy of predicting pelvic lymph node metastasis by investigating TBLR1 expression level (high vs low) could be as high as $50.2 \%$ (35.2\% plus $15 \%)$.

Human papillomavirus (HPV) infection is a necessary causal factor in cervical cancer development (Muňoz et al, 2003). The average HPV infection rate among different cervical cancer subgroups reached $99.7 \%$ in squamous cell carcinoma, whereas in adenocarcinoma and adenosquamous carcinoma it ranged from $94 \%$ to $100 \%$ (de Sanjose et al, 2010). Moreover, the E8^ ${ }^{\wedge} 2 \mathrm{C}$ protein has been studied in high-risk HPV, where it has shown to regulate viral genome levels and to repress transcription from the viral promoter (Laudadio, 2013). Interestingly, using an unbiased proteomic analysis, Powell et al (2010) identified six highconfidence candidate interacting proteins for $\mathrm{E} 8^{\wedge} \mathrm{E} 2 \mathrm{C}$ : the top two were NCoR1 and TBLR1. Consistent with previous study, we found TBLR1 was associated with HPV as well as progression of cervical cancer $(P<0.05)$.

Previously, it was observed that overexpression of TBLR1 could act as a novel diagnostic or therapeutic target in lung squamous cell carcinomas by immortalising a bronchial epithelial cell line that was considered 'precancerous' (An et al, 2003; Huang et al, 2009). Interestingly, TBLR1 was also amplified in breast cancer, where it might play an important part in progression (Perissi et al, 2008). Furthermore, knockdown of TBL1 and TBLR1 significantly suppressed the invasive growth of head and neck squamous cell carcinoma cells (Li and Wang, 2008), suggesting that TBLR1 may be required for tumourigenesis and metastasis. In the present study, the oncogenic potential of TBLR1 suggested by its ability to promote cervical cancer EMT in vitro and in vivo. Epithelial-mesenchymal transition plays key roles in determining cervical cancer risk factors, including invasion, metastatic dissemination and acquisition of therapeutic resistance of cancer cells (Polyak and Weinberg, 2009). Multiple different signalling pathways, including NF- $\kappa \mathrm{B}$, Wnt and JAK/STAT3, have been reported to regulate EMT in cervical cancer (Hsu et al, 2007; Mayrand et al, 2007; Li et al, 2009; Wu et al, 2013). Among them, NF- $\kappa \mathrm{B}$ has been reported to be constitutively activated in cervical cancer to promote EMT (Huang et al, 2009). Epigenetic silencing of SFRP genes contributed to cervical cancer progression through EMT by Wnt/ $\beta$-Catenin pathway (Chung et al, 2009). Notably, both NF- $\kappa$ B and Wnt/ $\beta$-Catenin pathways play vital roles in regulating EMT in cervical cancer. Interestingly, TBLR1 was reported to be essential for transcriptional activation of NF- $\kappa \mathrm{B}$ (Perissi et al, 2004, 2008). In addition, Perissi et al (2008) provided evidence that dedicated strategies based on the indispensible actions of TBLR1 were adopted by NF- $\kappa$ B-regulated genes in Hela cells. Depletion of TBLR1 by specific siRNAs in TNF- $\alpha$-stimulated endothelial cells result in significant inhibition of the NF- $\kappa \mathrm{B}$ dependent gene activation programme (Perissi et al, 2004). A prerequisite for NF- $\kappa \mathrm{B}$ transcription and survival is that SMRT is derepressed by $\mathrm{I} \kappa \mathrm{B}$ kinase $\alpha$ with a loss of HDAC 3 and with the recruitment of TBLR1 exchanged for co-activators (Grandori et al, 2000; Hoberg et al, 2004). On the other hand, mammalian TBLR1 was also shown to collaborate with Siah1 in a novel pathway for 
A

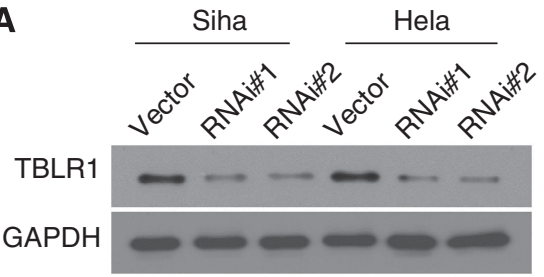

C

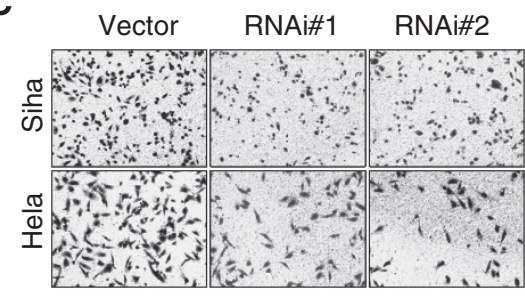

D

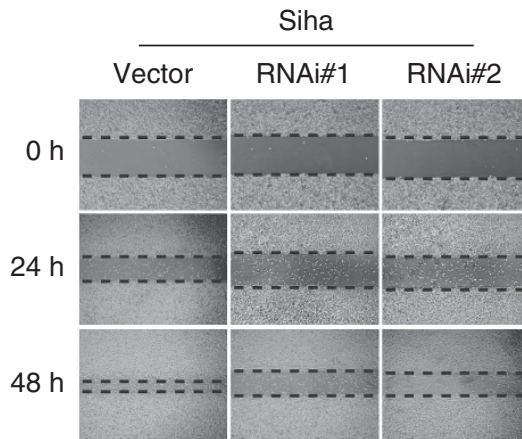

E

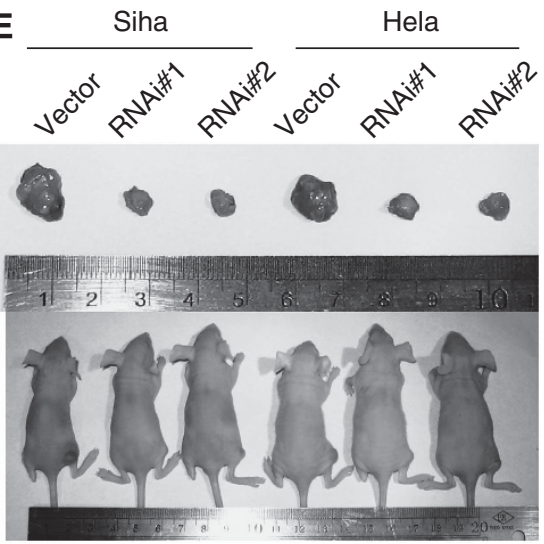

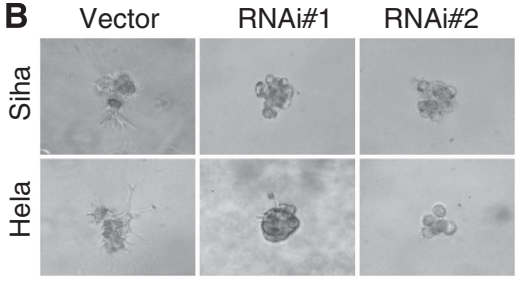
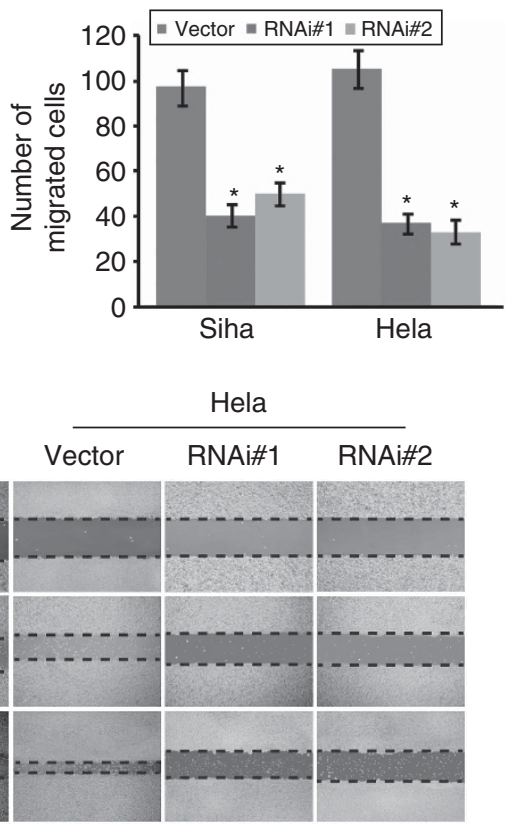

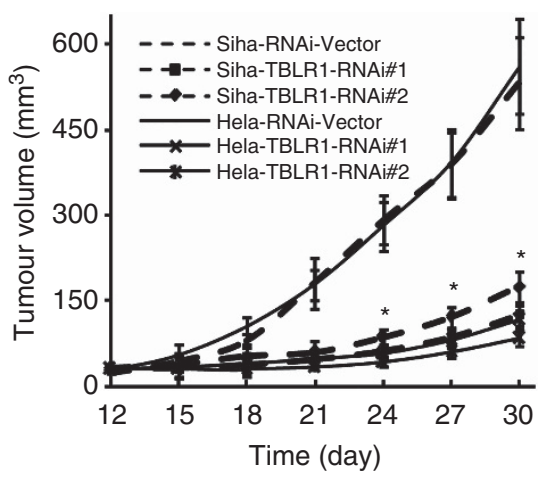

Figure 5. Downregulation of TBLR1 repressed cellular motility and invasion in vitro and in vivo. (A) Western blotting of the expression of TBLR1 in RNAi vector and TBLR1 shRNA 1- and 2-transduced Hela and Siha cells. Glyceraldehyde 3-phosphate dehydrogenase (GAPDH) was used as a loading control. (B) The acini formation of cells was tested in 3D morphogenesis Matrigel culture ( $\times 200)$. (C) The invasive properties induced by fetal bovine serum were analysed by the Boyden chamber invasion assay $(\times 200, * P<0.05)$. (D) Cell mobility was measured by testing the rate of wound closure at 0,24 and $48 \mathrm{~h}(\times 200)$. (E) Effect of TBLR1 on tumour formation in nude mouse xenograft model. A representative picture of tumour growth in nude mice subcutaneously inoculated with RNAi vector and TBLR1 shRNA 1- and 2-transduced Hela and Siha cells (left).

Subcutaneous tumour growth curve of TBLR1 shRNA 1- and 2-transduced Hela and Siha cells in nude mice was compared with RNAi vector Hela and Siha cells in nude mice $(n=6)$ (right). ${ }^{\star} P<0.05$.

$\beta$-catenin degradation. Furthermore, the role of TBLR1 in the promotion of $\mathrm{Wnt} / \beta$-catenin-mediated oncogenesis has been emphasised recently in a Wnt signalling-dependent manner (Yoon et al, 2005). In addition, TBLR1 may promote cervical cancer EMT as an indispensable factor for $\beta$-catenin-mediated invasive growth that plays a critical role in $\mathrm{p} 53$-induced $\beta$-catenin degradation, because knockdown of TBLR1 strongly inhibited tumour cell invasion through the Matrigel-coated membrane in head and neck squamous cell carcinoma (Li and Wang, 2008). Interestingly, previous studies show that TCF-4 mediates a nuclear response to Wnt signals by interacting with $\beta$-catenin, and TCF4-RNAi could then directly downregulate the expression of TCF- 4 as an effective inhibitor of $\mathrm{Wnt} / \beta$-Catenin pathway (Ravindranath et al, 2011; Zhang et al, 2011). Moreover, I $\kappa \mathrm{B} \alpha-\mathrm{mu}$ effectively inactivated the $\mathrm{I} \kappa \mathrm{B} \alpha$ protein (Cabannes et al, 1999), thus causing NF- $\kappa \mathrm{B}$ to be significantly inactive in the tumour cells and this activity contributes to the different malignant state of these tumour cells such as the inhibiting the progression of oesophageal squamous cell carcinoma (Song et al, 2012). In light of these findings, we further validated that both NF- $\kappa \mathrm{B}$ and 
A

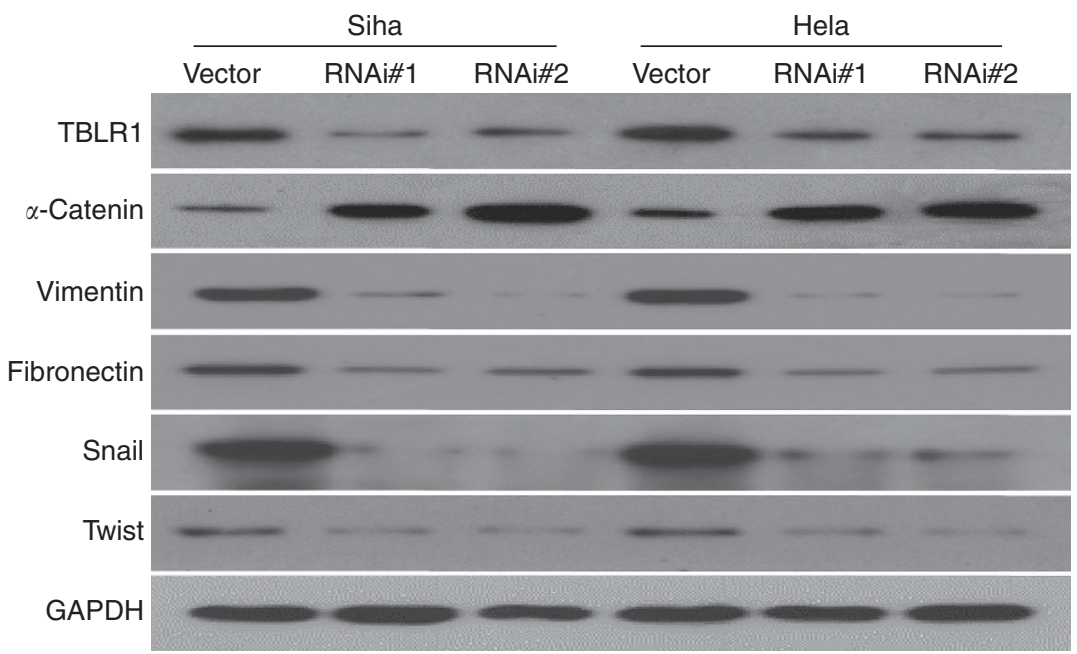

B

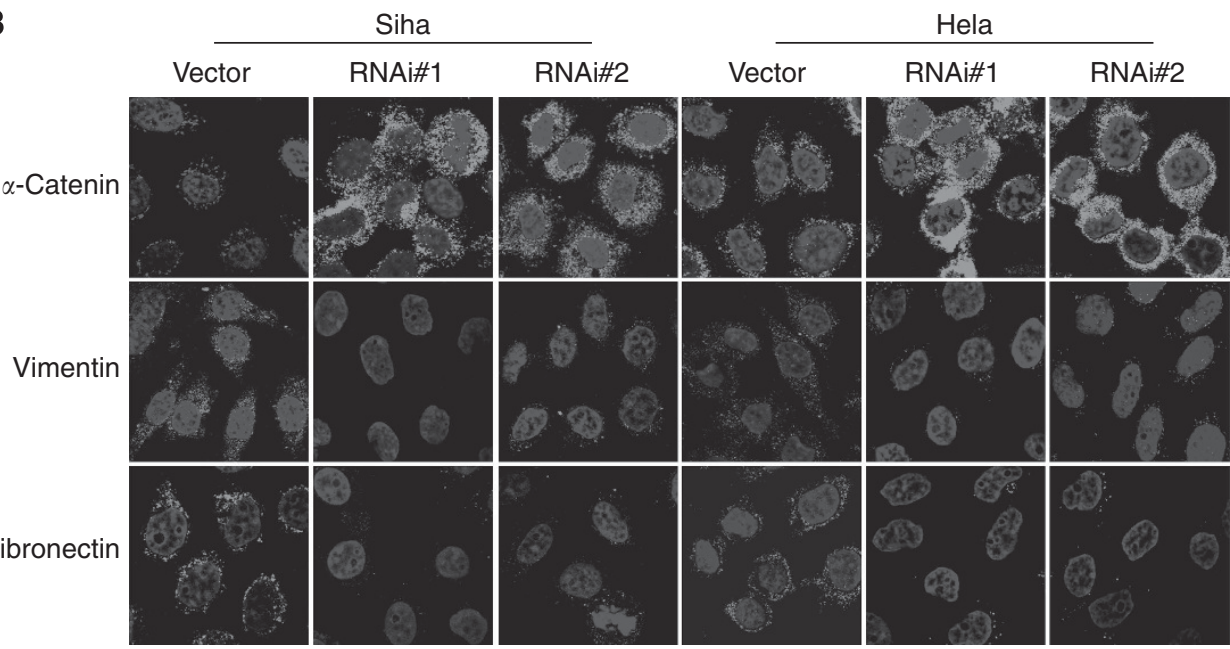

C

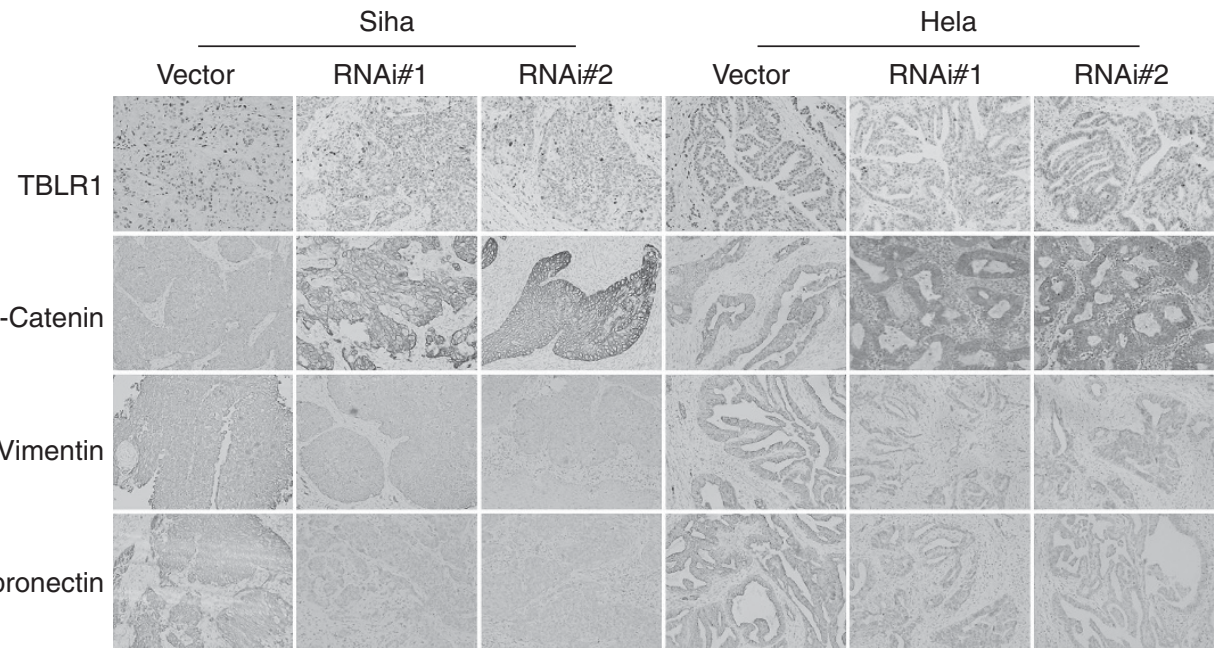

Figure 6. Knockdown of TBLR1 inhibited EMT by downregulating the expressions of Snail and Twist in cervical cancer. (A) Western blotting of the expressions of TBLR1 and EMT-relevant markers $\alpha$-Catenin, fibronectin and vimentin, as well as EMT regulators Snail and Twist in RNAi vector and TBLR1 shRNA 1- and 2-transduced Hela and Siha cells. Glyceraldehyde 3-phosphate dehydrogenase (GAPDH) was used as a loading control. (B) Immunofluorescence assay of EMT-relevant markers ( $\alpha$-Catenin, fibronectin, vimentin) $(\times 100)$. (C) The IHC assay of protein expression of TBLR1 and EMT-relevant markers ( $\alpha$-Catenin, fibronectin and vimentin) in the tumours excised from six groups of mice including the RNAi vector and TBLR1 shRNA 1- and 2-transduced Hela and Siha groups, respectively $(\times 200)$.

Wnt/ $\beta$-Catenin pathways, under the sophisticated regulation of TBLR1, play the essential roles in promoting EMT in cervical cancer by increasing the expression levels of EMT markers, including vimentin and fibronectin. Consistent with previous reports, we demonstrated that TBLR1 might contribute to invasion, metastasis and progression of cervical cancer, and silencing TBLR1 inhibited the EMT of human cervical cancer cells through NF- $\kappa \mathrm{B}$ and $\mathrm{Wnt} / \beta$-Catenin pathways. 
A

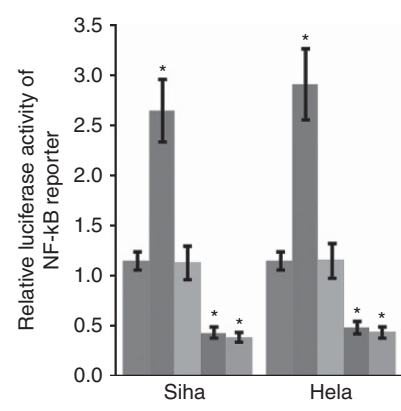

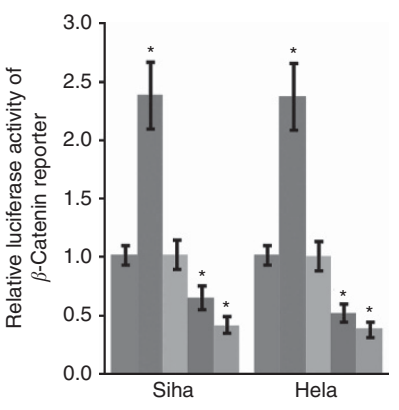

C

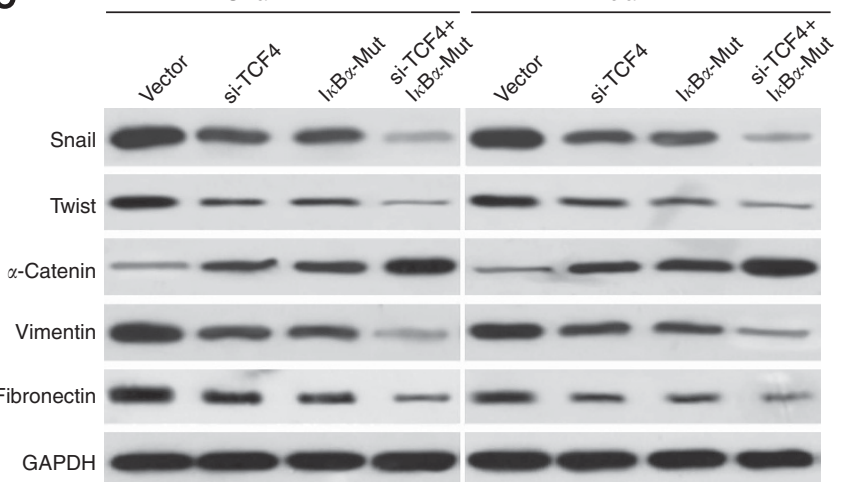

B

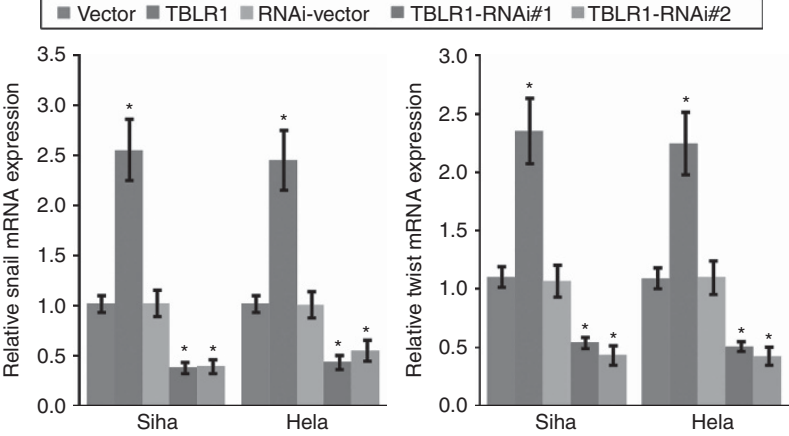

D

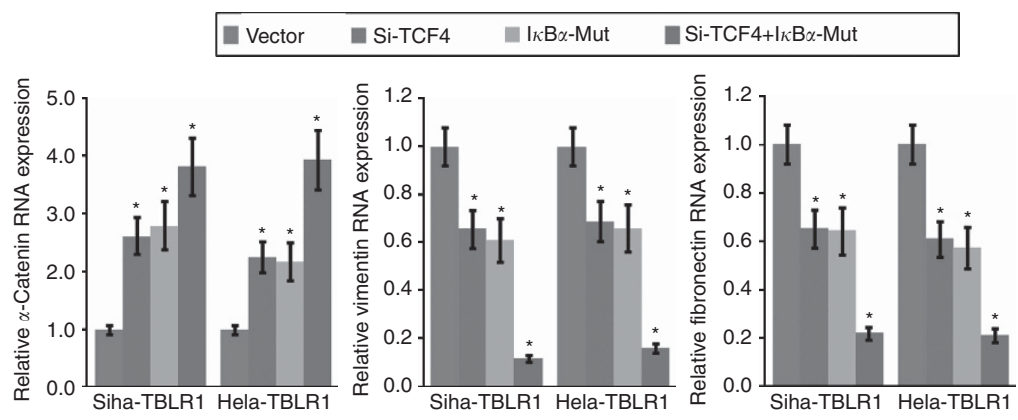

E
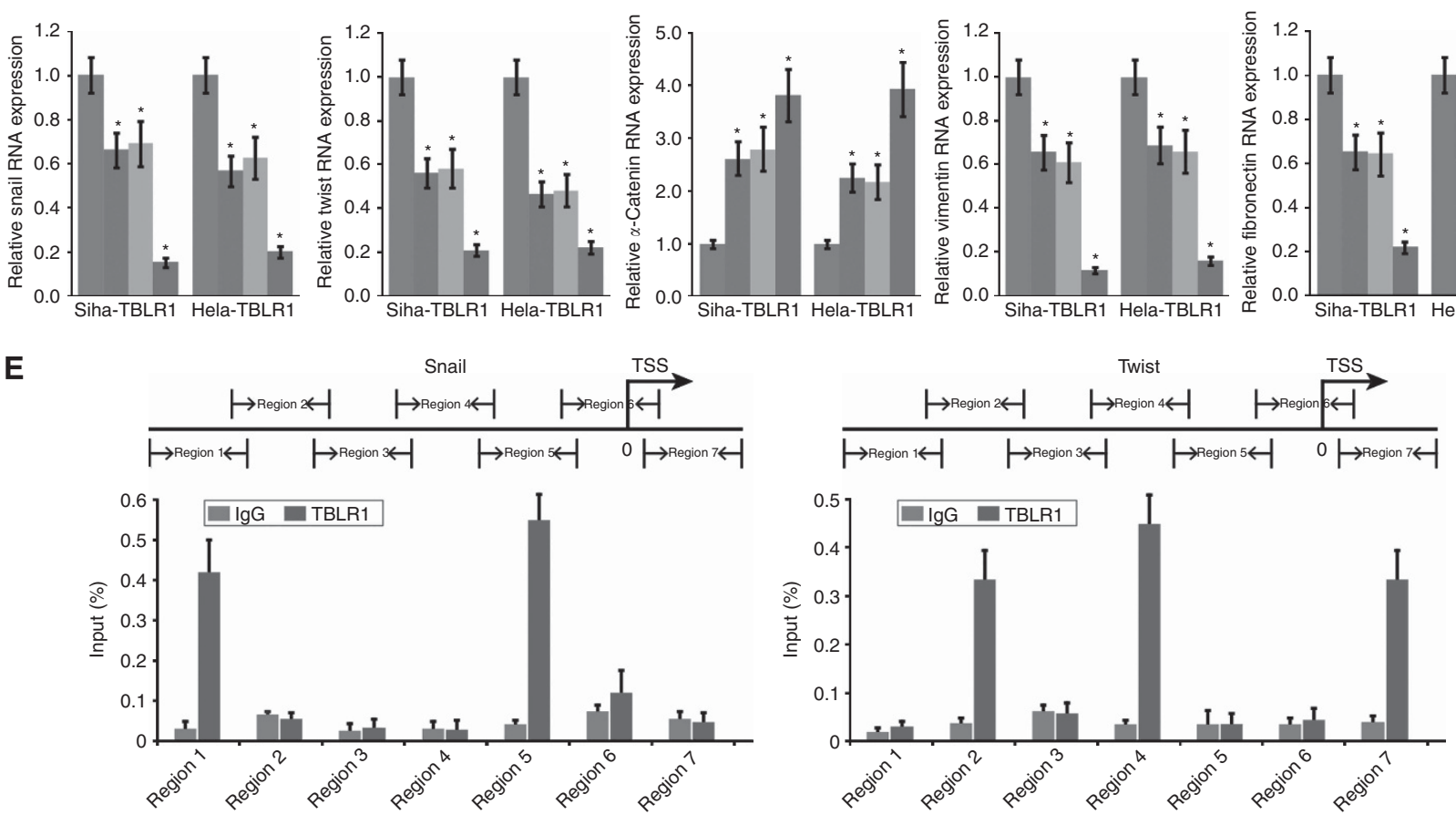

Figure 7. (A) Relative luciferase activities of NF- $k \mathrm{~B}$ and $\beta$-Catenin reporters, respectively, in the stable cell lines. Error bars represent the mean \pm s.d. from three independent experiments. (B) Real-time PCR analysis indicating an apparent overlap between TBLR1 and Snail mRNA expression, and between TBLR1 and Twist mRNA expression, respectively, in the stable Hela and Siha cells. Bars represent the mean \pm s.d. values. Experiments were performed in triplicate. (C) Western blotting of the expressions of EMT-relevant markers including $\alpha$-Catenin, fibronectin and vimentin and EMT regulators, Snail and Twist, in the stable TBLR1-overexpressing cells, and the stable TBLR1-overexpressing cells transfected with TCF4-RNAi or (and) I $\kappa$ B $\alpha-$-mu, respectively. Glyceraldehyde 3-phosphate dehydrogenase (GAPDH) was used as a loading control. (D) Real-time PCR analysis of the expressions of EMT-relevant markers including $\alpha$-Catenin, fibronectin, vimentin, Snail and Twist in the above cells, respectively. Bars represent the mean \pm s.d. values. Experiments were performed in triplicate. (E) Binding of TBLR1 to the Snail and Twist promoters was analysed by ChIP, respectively. The results display the means \pm s.e.m. performed in triplicate. ${ }^{*} P<0.05$. 
The molecular mechanisms underlying the role of TBLR1 in cervical cancer EMT in NF- $\kappa \mathrm{B}$ and $\mathrm{Wnt} / \beta$-Cantenin pathways, however, remain largely unknown. A preliminary study on the molecular mechanisms demonstrated the indispensable roles of Snail and Twist that were regulated by the NF- $\kappa \mathrm{B}$ and $\mathrm{Wnt} / \beta$ Catenin pathways. In cervical cancer, gene expression arrays have identified an increase in the expression of the EMT-related genes (Snail, Twist and E-cadherin) in lymph node micrometastases compared with the primary tumours (Julien et al, 2007; Hsu et al, 2007; Chung et al, 2009). Among the various signals associated with the EMT programme, Snail was a central transcription factor (Shagieva et al, 2012). Lee et al (2008) showed that EMT could be modulated by the signal from extracellular matrix fibronectin and $\alpha 5 \beta 1$ integrin in cervical cancer cells via upregulating Snail expression. Recently, Baritaki et al (2010) proposed that activation of the NF- $\kappa \mathrm{B}$ pathway regulated the expression of the EMT phenotype by inducing the Snail family of transcription factors. Snail was regulated as a direct target of NF- $\kappa \mathrm{B}$ to promote EMT via the amyl hydrocarbon receptor (Barberà et al, 2004; Min et al, 2008). Twist2 overexpression was also significantly linked to cervical cancer progression, in combination with aberrant E-cadherin expression in primary cervical cancer tissues, predicting the malignant transformation and distal metastasis (Shibata et al, 2008; Li et al, 2012). Moreover, SFRP1 and SFRP2 have been demonstrated to suppress EMT in cervical cancer by enhancing E-cadherin through inhibition of Snail and Twist that were regulated by Wnt/ $\beta$-Catenin pathway (Chung et al, 2009). Consistent with previous studies, our findings provided further insights into the contribution of Snail and Twist as downstream signal molecules of NF- $\kappa \mathrm{B}$ and $\mathrm{Wnt} / \beta$-Catenin signalling pathways in promoting EMT, further enhancing the invasion and metastasis of cervical cancer.

In conclusion, we have demonstrated an important role for TBLR1 in cervical cancer, where it is remarkably associated with poor prognosis and enhanced progression of cervical cancer. Future studies, which are already underway in our laboratory, should address the detailed molecular mechanisms underlying the role of TBLR1 in the carcinogenesis and the exact relationship between TBLR1 and HPV infection of cervical cancer.

\section{ACKNOWLEDGEMENTS}

This study was funded by the Natural Science Foundation of Guangdong (S2013010015552, S2011010003516 and S2012040006483), the National Natural Science Foundation of China (81302550) and The Postdoctoral Science Foundation of China (2013M530382).

\section{REFERENCES}

Altgassen C, Hertel H, Brandstädt A, Kohler C, Dürst M, Schneider A (2008) Multicenter validation study of the sentinel lymph node concept in cervical cancer: AGO Study Group. J Clin Oncol 26: 2943-2951.

An Q, Pacyna-Gengelbach M, Schlüns K, Deutschmann N, Guo S, Gao Y, Zhang J, Cheng S, Petersen I (2003) Identification of differentially expressed genes in immortalized human bronchial epithelial cell line as a model for in vitro study of lung carcinogenesis. Int J Cancer 103: 194-204.

Andersson S, Wallin KL, Hellstrom AC, Morrison LE, Hjerpe A, Auer G, Ried T, Larsson C, Heselmeyer-Haddad K (2006) Frequent gain of the human telomerase gene TERC at 3q26 in cervical adenocarcinomas. Br J Cancer 95: 331-338.

Barberà MJ, Puig I, Domínguez D, Julien-Grille S, Guaita-Esteruelas S, Peiró S, Baulida J, Francí C, Dedhar S, Larue L (2004) Regulation of Snail transcription during epithelial to mesenchymal transition of tumor cells. Oncogene 23: 7345-7354.

Baritaki S, Huerta-Yepez S, Sahakyan A, Karagiannides I, Bakirtzi K, Jazirehi A, Bonavida B (2010) Mechanisms of nitric oxide-mediated inhibition of
EMT in cancer: inhibition of the metastasis-inducer Snail and induction of the metastasis-suppressor RKIP. Cell Cycle 9: 4931-4940.

Benedet JL, Bender H, Jones HR, Ngan HY, Pecorelli S (2000) FIGO staging classifications and clinical practice guidelines in the management of gynecologic cancers. FIGO Committee on Gynecologic Oncology. Int J Gynaecol Obstet 70: 209-262.

Biewenga P, van der Velden J, Mol BW, Stalpers LJ, Schilthuis MS, van der Steeg JW, Burger MP, Buist MR (2011) Prognostic model for survival in patients with early stage cervical cancer. Cancer 117: 768-776.

Cabannes E, Khan G, Aillet F, Jarrett RF, Hay RT (1999) Mutations in the I $\mathrm{B} \alpha$ gene in Hodgkin's disease suggest a tumour suppressor role for I $\mathrm{I} B \alpha$. Oncogene 18: 3063-3070.

Chen Y, Zhang L, Tian J, Fu X, Ren X, Hao Q (2013) Significance of the absolute number and ratio of metastatic lymph nodes in predicting postoperative survival for the International Federation of Gynecology and Obstetrics stage IA2 to IIA cervical cancer. Int J Gynecol Cancer 23: 157-163.

Choi HK, Choi KC, Yoo JY, Song M, Ko SJ, Kim CH, Ahn JH, Chun KH, Yook JI, Yoon HG (2011) Reversible SUMOylation of TBL1-TBLR1 regulates beta-catenin-mediated Wnt signaling. Mol Cell 43: 203-216.

Chung MT, Lai HC, Sytwu HK, Yan MD, Shih YL, Chang CC, Yu MH, Liu HS, Chu DW, Lin YW (2009) SFRP1 and SFRP2 suppress the transformation and invasion abilities of cervical cancer cells through Wnt signal pathway. Gynecol Oncol 112: 646-653.

de Sanjose S, Quint WG, Alemany L, Geraets DT, Klaustermeier JE, Lloveras B, Tous S, Felix A, Bravo LE, Shin H (2010) Human papillomavirus genotype attribution in invasive cervical cancer: a retrospective cross-sectional worldwide study. Lancet Oncol 11: 1048-1056.

Garg M, Kanojia D, Saini S, Suri S, Gupta A, Surolia A, Suri A (2010) Germ cell-specific heat shock protein 70-2 is expressed in cervical carcinoma and is involved in the growth, migration, and invasion of cervical cells. Cancer 116: 3785-3796.

Grandori C, Cowley SM, James LP, Eisenman RN (2000) The Myc/Max/Mad network and the transcriptional control of cell behavior. Annu Rev Cell Dev Bi 16: 653-699.

Hoberg JE, Yeung F, Mayo MW (2004) SMRT derepression by the IkappaB kinase alpha: a prerequisite to NF-kappaB transcription and survival. Mol Cell 16: 245-255.

Hsu YM, Chen YF, Chou CY, Tang MJ, Chen JH, Wilkins RJ, Ellory JC, Shen MR (2007) KCl cotransporter-3 down-regulates E-cadherin/betacatenin complex to promote epithelial-mesenchymal transition. Cancer Res 67: 11064-11073.

Huang A, Hsu S, Kuo C, Liao C, Lai K, Lin T, Wu S, Lu H, Tang N, Yang J (2009) Involvement of Matrix Metalloproteinases in the Inhibition of Cell Invasion and Migration Through the Inhibition of NF- $\mathrm{KB}$ by the New Synthesized Ethyl 2-[Np-chlorobenzyl-(2'-methyl)] anilino-4-oxo-4, 5dihydrofuran-3-carboxylate (JOTO1007) in Human Cervical Cancer CaSki Cells. In Vivo 23: 613-619.

Ishii S, Kurasawa Y, Wong J, Yu-Lee LY (2008) Histone deacetylase 3 localizes to the mitotic spindle and is required for kinetochore-microtubule attachment. Proc Natl Acad Sci USA 105: 4179-4184.

Jemal A, Bray F, Center MM, Ferlay J, Ward E, Forman D (2011) Global cancer statistics. CA Cancer J Clin 61: 69-90.

Julien S, Puig I, Caretti E, Bonaventure J, Nelles L, van Roy F, Dargemont C, de Herreros AG, Bellacosa A, Larue L (2007) Activation of NF-kappaB by Akt upregulates Snail expression and induces epithelium mesenchyme transition. Oncogene 26: 7445-7756.

Kodama J, Seki N, Masahiro S, Kusumoto T, Nakamura K, Hongo A, Hiramatsu Y (2010) Prognostic factors in stage IB-IIB cervical adenocarcinoma patients treated with radical hysterectomy and pelvic lymphadenectomy. J Surg Oncol 101: 413-417.

Kumar V, Behera R, Lohite K, Karnik S, Kundu GC (2010) p38 kinase is crucial for osteopontin-induced furin expression that supports cervical cancer progression. Cancer Res 70: 10381-10391.

Laudadio J (2013) Human papillomavirus detection: testing methodologies and their clinical utility in cervical cancer screening. Adv Anat Pathol 20 158-167.

Lee MY, Chou CY, Tang MJ, Shen MR (2008) Epithelial-mesenchymal transition in cervical cancer: correlation with tumor progression, epidermal growth factor receptor overexpression, and snail up-regulation. Clin Cancer Res 14: 4743-4750. 
Li J, Jia H, Xie L, Wang X, Wang X, He H, Lin Y, Hu L (2009) Association of constitutive nuclear factor-kappaB activation with aggressive aspects and poor prognosis in cervical cancer. Int J Gynecol Cancer 19: 1421-1426.

Li J, Wang C (2008) TBL1-TBLR1 and beta-catenin recruit each other to Wnt target-gene promoter for transcription activation and oncogenesis. Nat Cell Biol 10: 160-169.

Li Y, Wang W, Wang W, Yang R, Wang T, Su T, Weng D, Tao T, Li W, Ma D, Wang S (2012) Correlation of TWIST2 up-regulation and epithelialmesenchymal transition during tumorigenesis and progression of cervical carcinoma. Gynecol Oncol 124: 112-118.

Mayrand MH, Duarte-Franco E, Rodrigues I, Walter SD, Hanley J, Ferenczy A, Ratnam S, Coutlée F, Franco EL (2007) Human papillomavirus DNA versus Papanicolaou screening tests for cervical cancer. N Engl J Med 357: 1579-1588.

Min C, Eddy SF, Sherr DH, Sonenshein GE (2008) NF-kappaB and epithelial to mesenchymal transition of cancer. J Cell Biochem 104: 733-744.

Muňoz N, Bosch FX, de Sanjosé S, Herrero R, Castellsagué X, Shah KV, Snijders PJ, Meijer CJ (2003) Epidemiologic classification of human papillomavirus types associated with cervical cancer. New Engl J Med 348: 518-527.

Noordhuis MG, Fehrmann RS, Wisman GB, Nijhuis ER, van Zanden JJ, Moerland PD, LVTE Ver, Volders HH, Kok M, Ten HK, Hollema H, de Vries EG, de Bock GH, van der Zee AG, Schuuring E (2011) Involvement of the TGF-beta and beta-catenin pathways in pelvic lymph node metastasis in early-stage cervical cancer. Clin Cancer Res 17: 1317-1330.

Perissi V, Aggarwal A, Glass CK, Rose DW, Rosenfeld MG (2004) A corepressor/coactivator exchange complex required for transcriptional activation by nuclear receptors and other regulated transcription factors. Cell 116: 511-526.

Perissi V, Scafoglio C, Zhang J, Ohgi KA, Rose DW, Glass CK, Rosenfeld MG (2008) TBL1 and TBLR1 phosphorylation on regulated gene promoters overcomes dual CtBP and NCoR/SMRT transcriptional repression checkpoints. Mol Cell 29: 755-766.

Polyak K, Weinberg RA (2009) Transitions between epithelial and mesenchymal states: acquisition of malignant and stem cell traits. Nat Rev Cancer 9: 265-273.

Powell ML, Smith JA, Sowa ME, Harper JW, Iftner T, Stubenrauch F, Howley PM (2010) NCoR1 mediates papillomavirus E8^ ${ }^{\wedge} 2 \mathrm{C}$ transcriptional repression. J Virol 84: 4451-4460.

Ravindranath A, Yuen HF, Chan KK, Grills C, Fennell DA, Lappin TR, ElTanani M (2011) Wnt- $\beta$-Catenin-Tcf- 4 signalling-modulated invasiveness is dependent on osteopontin expression in breast cancer. Brit J Cancer 105: $542-551$.

Selman TJ, Mann C, Zamora J, Appleyard TL, Khan K (2008) Diagnostic accuracy of tests for lymph node status in primary cervical cancer: a systematic review and meta-analysis. CMAJ 178: 855-862.

Shagieva GS, Domnina LV, Chipysheva TA, Ermilova VD, Chaponnier C, Dugina VB (2012) Actin isoforms and reorganization of adhesion junctions in epithelial-to-mesenchymal transition of cervical carcinoma cells. Biochemistry (Mosc) 77: 1266-1276.
Shibata K, Kajiyama H, Ino K, Terauchi M, Yamamoto E, Nawa A, Nomura S, Kikkawa F (2008) Twist expression in patients with cervical cancer is associated with poor disease outcome. Ann Oncol 19: 81-85.

Siegel R, Ward E, Brawley O, Jemal A (2011) Cancer statistics, 2011. CA Cancer J Clin 61: 212-236.

Slama J, Dundr P, Dusek L, Cibula D (2013) High false negative rate of frozen section examination of sentinel lymph nodes in patients with cervical cancer. Gynecol Oncol 129: 384-388.

Song L, Gong H, Lin C, Wang C, Liu L, Wu J, Li M, Li J (2012) Flotillin-1 promotes tumor necrosis factor- $\alpha$ receptor signaling and activation of NF- $\kappa \mathrm{B}$ in esophageal squamous cell carcinoma cells. Gastroenterology 143: 995-1005.

Song LB, Li J, Liao WT, Feng Y, Yu CP, Hu LJ, Kong QL, Xu LH, Zhang X, Liu WL, Li MZ, Zhang L, Tsao SW, Li M, Band V, Band H, Shi QH, Zeng YX, Zeng MS (2009) The polycomb group protein Bmi-1 represses the tumor suppressor PTEN and induces epithelial-mesenchymal transition in human nasopharyngeal epithelial cells. J Clin Invest 119: 3626-3636.

Wangsa D, Heselmeyer-Haddad K, Ried P, Eriksson E, Schäffer AA, Morrison LE, Luo J, Auer G, Munck-Wikland E, Ried T, Lundqvist EÅ (2009) Fluorescence in situ hybridization markers for prediction of cervical lymph node metastases. Am J Pathol 175: 2637-2645.

Workman P, Aboagye EO, Balkwill F, Balmain A, Bruder G, Chaplin DJ, Double JA, Everitt J, Farningham D, Glennie MJ, Kelland LR, Robinson V, Stratford IJ, Tozer GM, Watson S, Wedge SR, Eccles SA. An ad hoc committee of the National Cancer Research Institute (2010) Guidelines for the welfare and use of animals in cancer research. Br J Cancer 102: 1555-1577.

Wu Z, Peng X, Li J, Zhang Y, Hu L (2013) Constitutive activation of nuclear factor kappaB contributes to cystic fibrosis transmembrane conductance regulator expression and promotes human cervical cancer progression and poor prognosis. Int J Gynecol Cancer 23: 906-915.

Yang YC, Shyong WY, Chang MS, Chen YJ, Lin CH, Huang ZD, Wang, Hsu MT, Chen ML (2001) Frequent gain of copy number on the long arm of chromosome 3 in human cervical adenocarcinoma. Cancer Genet Cytogenet 131: 48-53.

Yoon HG, Choi Y, Cole PA, Wong J (2005) Reading and function of a histone code involved in targeting corepressor complexes for repression. Mol Cell Biol 25(1): 324-335.

Zhang J, Huang K, Shi Z, Zou J, Wang Y, Jia Z, Zhang A, Han L, Yue X, Liu N (2011) High $\beta$-catenin/Tcf-4 activity confers glioma progression via direct regulation of AKT2 gene expression. Neuro Oncol 13: 600-609.

Zhang J, Kalkum M, Chait BT, Roeder RG (2002) The N-CoR-HDAC3 nuclear receptor corepressor complex inhibits the JNK pathway through the integral subunit GPS2. Mol Cell 9: 611-662.

This work is published under the standard license to publish agreement. After 12 months the work will become freely available and the license terms will switch to a Creative Commons AttributionNonCommercial-Share Alike 3.0 Unported License.

Supplementary Information accompanies this paper on British Journal of Cancer website (http://www.nature.com/bjc) 